\title{
Da formação contínua de professores ao desenvolvimento docente - o grupo colaborativo e seu potencial mediador
}

\author{
From continuing teacher education to \\ teacher development - the collaborative group and \\ its mediating potential
}

\author{
Luciana Guimarães PEDRO 1 \\ Geovana Ferreira MELO ${ }^{2}$
}

\begin{abstract}
Resumo
Esse artigo refere-se a uma pesquisa que objetivou compreender o processo de desenvolvimento profissional docente no movimento de um grupo colaborativo. Baseado na Pesquisa Colaborativa realizou-se um curso de extensão, cujas audiogravações foram analisadas segundo a proposta dos Núcleos de Significação. Concluiu-se que o grupo colaborativo se consolidou como mediador relevante para o desenvolvimento docente; que a mediação do outro e os dramas vividos pelos professores sáo propulsores de desenvolvimento e que as decisóes pedagógicas pautadas pela afetividade são determinantes num grupo. Por fim, apresentou-se pressupostos para inspirar a construçáo de grupos colaborativos como proposta de formação contínua para professores.
\end{abstract}

Palavras-chave: Desenvolvimento Profissional Docente. Grupo Colaborativo. Mediação.
Abstract

This article is about a research that aims to understand the professional process development of teachers in a perspective of the movement of a collaborative group. Based on a Collaborative Research, an extension course was carried out, whose audio recordings were subsequently analyzed by two Significance Centers. It was concluded that the collaborative group consolidated itself as a relevant mediator for teacher development; that mediation of other and dramas experienced by teachers are propellers of development and that pedagogical decisions based on affectivity are determinant in our group. Finally, it is proposed to inspire the construction of collaborative groups as a proposal for continuing teacher education.

Key-works: Professional Teacher Development. Collaborative Group. Mediation.

1 Pós-doutorado em Educação - UFU, Membro da Gestão da Escola Parque Tibetano. Lattes: http:// lattes.cnpq.br/4083571355399619. Orcid: http://orcid.org/0000-0002-0806-8814. E-mail: lucianaguimaraespedro@gmail.com

2 Pós-doutorado em Educação - USP, Professora Associada da Universidade Federal de Uberlândia - UFU. Lattes: http://lattes.cnpq.br/8047532255499546. Orcid: https://orcid.org/0000-0001-8406-6223. E-mail: geovana.melo@ufu.br 


\section{Introdução}

Considerando os inúmeros desafios vivenciados pelos professores em sua atuação profissional, o presente relato de pesquisa faz menção à tese de doutorado intitulada "Como se fora brincadeira de roda - o grupo colaborativo como mediador do desenvolvimento docente". A investigação realizada no âmbito da Linha de Pesquisa em Saberes e Práticas Educativas do Programa de Pósgraduação em Educação da Universidade Federal de Uberlândia (UFU), contou com o apoio financeiro da Fundação de Amparo à Pesquisa do Estado de Minas (FAPEMIG) e teve parecer favorável do Comitê de Ética em Pesquisa da UFU. Portanto, o manuscrito respeita os procedimentos éticos exigidos em trabalhos de pesquisa.

A investigação em questão teve como temática o desenvolvimento profissional docente e objetivou apreender e analisar o processo de desenvolvimento profissional docente no movimento de um grupo colaborativo. Para isso, realizou, como proposta de formação contínua, um curso de extensão universitária voltado a professores licenciados, com até seis anos de experiência profissional, que atuavam no Ensino Fundamental II e Ensino Médio de escolas públicas municipais e estaduais de Uberlândia e seus arredores.

Para o desenvolvimento desta proposta formativa, tomou-se como subsídios: os conhecimentos da Educação que compreendem à docência como profissão; os princípios da Teoria Histórico-Cultural e seus conceitos; as discussóes sobre o processo de escolarização promovidas pela Psicologia Escolar e Educacional numa vertente crítica e as orientaçóes trazidas pela Pesquisa Colaborativa.

\section{O desenvolvimento profissional docente à luz da Teoria Histórico Cultural}

A docência é uma profissão complexa! Não nos tornamos professores apenas e pontualmente fazendo um curso superior. Essa profissão exige conhecimentos específicos, além de envolver vivências experimentadas diária e continuamente ao longo da vida do docente.

O processo pelo qual o indivíduo se torna professor é histórico [...]. Na trama das relaçóes sociais de seu tempo, os indivíduos que se fazem professores vão se apropriando das vivências práticas e intelectuais, de valores éticos e das normas que regem o cotidiano educativo e as relaçóes no interior e exterior do corpo docente. (FONTANA, 1997, p. 54) 
A constituição do professor se dá pela internalização de conceitos científicos específicos, de vivências experimentadas pelos diferentes papéis ocupados na escola e, também, por meio de suas demais açóes no mundo. Sendo o professor um sujeito uno, o pessoal e o profissional não são aspectos distintos em seu ser, uma vez que, "não é possível separar o eu pessoal do eu profissional" (NÓVOA, 1992, p.7).

A formação de professores ao longo da história vem acontecendo nos espaços de ensino formais, ou seja, em instituições sociais que se materializam em condições histórico-culturais específicas, sendo, por isso, determinadas por relaçôes políticas, econômicas, sociais, culturais e históricas (SOUZA, 2006).

As Universidades, desde o início do século $\mathrm{XX}$, são responsáveis pela formação dos mais diversos profissionais, incluindo os professores. No que se refere, especificamente, à formação desse profissional observamos a ocorrência de diferentes movimentos de reformas nas Políticas Públicas da Educação, com o intuito de organizar o currículo das instituiçóes de ensino superior de modo a atender às demandas de cada época vivida (MOREIRA, 1990).

$\mathrm{Na}$ contemporaneidade, para se falar de formaçáo docente é necessário considerar o Plano Nacional de Educação (PNE), Lei no $13.005 / 2014$ e as Diretrizes Curriculares para a Formaçáo Inicial e Continuada de Professores (DCN), Resolução 02/2015.

O PNE é um instrumento de planejamento do Estado democrático construído com a participação das diferentes instâncias sociais e do poder público (BRASIL, 2014). Ele traz orientaçóes de execução e aprimoramento das políticas públicas de educação do Brasil. O PNE 2014-2024 dá ênfase à preocupação com a democratização do ensino, ao oferecimento de uma educação superior de qualidade e ao investimento em formação contínua para os docentes.

De modo convergente, as Diretrizes Curriculares Nacionais para a Formação Inicial e Continuada de professores (DCN) da Resolução 02/2015, apontam para uma proposta de formação de professores complexa, plurideterminada e permanente. Essa proposta supera a ideia central de competências, predominante na perspectiva da racionalidade técnica, em que o professor tinha seu papel reduzido a mero técnico do ensino que, em meio à burocracia escolar, precisava "administrar e implementar programas curriculares, mais do que desenvolver ou apropriar-se criticamente de currículos que satisfaçam objetivos pedagógicos específicos" (GIROUX, 1997, p. 161).

$\mathrm{Na}$ perspectiva das DCN temos a ascendência de um modelo formativo baseado na concepção de desenvolvimento docente. Essa vertente considera o professor como um profissional que se constitui ao longo de toda a sua vida. Isto vai ao encontro das ideias do paradigma da complexidade no que diz respeito à formação de professores, uma vez que aponta para a importância de 
uma qualificação contínua dos professores pautada por fundamentos críticos e reflexivos (BEHRENS, 2007).

Quando se fala em desenvolvimento profissional docente, considera-se, portanto, que os processos formativos, tanto inicial como contínuos, constituemse em espaços-tempo essenciais para promover transformaçóes nas concepçóes cristalizadas ao longo da vida acadêmica e profissional dos professores. Assim, o aprendizado da docência náo se limita ao que chamamos de formação inicial, aquela que se restringe ao curso de graduação, nem táo pouco a momentos específicos de aprimoramento profissional. Ele acontece de forma contínua, ao longo da vida do professor por meio da internalização de saberes específicos dessa profissão e das vivências experimentadas pelo sujeito.

Sobre os saberes docentes, que são os saberes específicos da profissão de professor, Tardif (2000, 2011), Gauthier (1998) e Pimenta (2000) trazem contribuiçóes importantes que, apesar de distintas, convergem no sentido de indicar que os saberes necessários ao exercício da docência constituem a prática pedagógica do professor e determinam suas concepçóes sobre educação, políticas públicas; o seu posicionamento em sala de aula, a relaçáo com os estudantes e parceiros de trabalho; as metodologias de ensino utilizadas, as atividades avaliativas escolhidas, como também o sentido da docência e sua identidade profissional.

A identidade profissional do professor, não é simplesmente construída no curso de formação inicial e lapidada nas experiências de formação contínua. Ao contrário, ela se determina por meio de um processo longo e complexo em que o docente agrega às vivências experimentadas nos distintos setores de sua vida, os diferentes saberes construídos, definindo, assim, o seu modo de ser profissionalmente.

Definir a identidade profissional faz parte de um processo de construçáo de um dado sujeito historicamente situado (PIMENTA, 2000). Assim, "compreender como se reproduzem e se transformam as identidades, implica esclarecer os processos de socializaçáo através dos quais elas se constroem e se reconstroem ao longo da vida” (DUBAR, 1999, p. 241). A identidade profissional não é, portanto, definitiva, é um constante construir-se que se dá na relação consigo, com o outro e o mundo.

Desse modo, o processo de construção da identidade profissional está relacionado, mais especificamente, com o modo como o sujeito se reconhece, atribui sentido a sua atuação profissional e é reconhecido pelos outros. Isso envolve aspectos da subjetividade de cada sujeito profissional (GONZÁLEZ REY, 2005), uma vez que tornar-se professor envolve um contínuo e permanente processo de desenvolvimento profissional.

Para Marcelo Garcia (2009), o conceito de desenvolvimento profissional docente engloba sete pontos principais: a ideia de que o professor é um sujeito que 
aprende de forma ativa; que o desenvolvimento profissional é um processo que acontece a longo prazo, estabelecendo uma relação entre conhecimentos prévios e novas experiências; que se dá por meio das atividades diárias do professor na escola; que está relacionado com os processos de transformação da cultura da escola; que o professor aprende continuamente por meio da práxis profissional; que a constituição profissional ocorre de forma colaborativa e que é tarefa da escola avaliar constantemente suas necessidades e práticas como instituição de ensino.

Nessa perspectiva, o desenvolvimento profissional docente trata-se de um processo de (trans)formação, que visa o crescimento profissional e pessoal que vai se estabelecendo pela forma como o professor aprende a ensinar. Logo, as concepçóes - baseadas em vivências pessoais, em conhecimentos das disciplinas ligadas ao ensinar e em experiências escolares - já trazidas pelos professores em formação acerca do ensino, influem diretamente na forma como aprendem, nos processos de mudança que realizam internamente e, consequentemente, na forma como atuam como professor.

Como sujeito que se constitui histórico-culturalmente a partir da relação com o outro e o mundo, o professor forja-se por meio das relaçóes que estabelece com a materialidade da vida, tendo a palavra como mediador principal (LEONTIEV, 1978; ASBAHR, 2005; SMOLKA, 2004). Logo, as relaçôes sociais são determinantes para o desenvolvimento do sujeito (VIGOTSKI, 1997; PINO, 2005).

E como o ser humano se desenvolve? O desenvolvimento do sujeito acontece na medida em que, internalizando os elementos da cultura, ele tece novos sentidos sobre si e as coisas do mundo, criando pensamentos que representam um avanço qualitativo na estruturação de sua cogniçẫo (VIGOTSKI, 1988; VERESOV, 2010). Esse processo atinente ao aprender, se dá em situaçóes sociais de desenvolvimento específicas que, para além da mera experiência externa de algo, referem-se, na verdade, a uma vivência que envolve "necessariamente qualidades emocionais e uma série de sensaçôes e percepções" (TOASSA, 2009, p. 61) que marcam o sujeito indelevelmente.

Portanto, o processo de desenvolvimento e aprendizagem humano é mediado pelas relaçóes sociais, ou seja, pelo encontro com o outro. De modo convergente, quando pensamos no desenvolvimento profissional docente constatamos que ele se dá também por meio das trocas estabelecidas com seus colegas de profissão. Nesse sentido, na pesquisa a qual fazemos referência aqui, o grupo colaborativo se evidenciou como uma situação social promotora de desenvolvimento.

Porém, o grupo não foi tomado como um elemento estático que encerra em si a capacidade de promover desenvolvimento (VIGOTSKI, 2010, p. 682). Ao contrário, buscou-se compreender o desenvolvimento dos sujeitos envolvidos no grupo, no movimento do próprio grupo, considerando-o dentro de um contexto social específico que também estava em movimento. 
O foco foi dado na vivência dos sujeitos no contexto do grupo colaborativo, ou seja, na unidade entre a relaçáo de cada professor colaborador, considerando sua subjetividade, e a realidade vivida durante os encontros formativos (PRESTES, 2010). Logo, buscou-se compreender o modo como cada professor tornava-se consciente, interpretava e se relacionava emocionalmente com a vivência em grupo acerca da profissão docente (VIGOTSKI, 1998).

Considerando que o homem como ser social que é, está imerso em diferentes relaçóes e que ele se transforma e se constitui movido por dramas, ou seja, interações sociais que geram colisão, crise (VERESOV, 2010), o relato de pesquisa em questão enfatizará as vivências dramáticas experimentadas pelos professores no movimento do grupo colaborativo, proposto como ferramenta para a formação contínua docente.

\section{O grupo colaborativo e o material empírico da pesquisa}

A pesquisa de doutorado a qual este artigo se refere trata-se de uma investigação de caráter qualitativo do tipo colaborativa, que teve como referência principal os escritos de Ibiapina na obra "Pesquisa Colaborativa: investigação, formação e produção de conhecimento", publicada em 2008.

A pesquisa colaborativa visa criar espaço de estudo, reflexão e construção de novos conhecimentos e possibilidades de ação diante dos desafios educacionais. É uma metodologia do tipo emancipatória que tem como característica: a unidade entre teoria e prática; a reflexão crítica sobre o campo de atuação dos docentes; o olhar para as questóes sociopolíticas que determinam a realidade e a horizontalidade nas relaçóes estabelecidas entre os colaboradores, tendo em vista a coprodução de conhecimentos sobre e para a educaçáo, por meio da compreensáo das condiçóes concretas do trabalho do professor (IBIAPINA, 2008).

Desse modo, o desenvolvimento de um trabalho colaborativo implica em constituir um grupo de sujeitos que tenham interesses pessoais, profissionais e sociais comuns que estejam disponíveis para refletir sobre um dado tema, baseado no respeito mútuo e na qualificação do saber-fazer de cada sujeito envolvido, culminando em uma formação democrática, coletiva, reflexiva, crítica, politizada, dialógica e feita por e entre pares.

Segundo Ibiapina (2008), para desenvolver academicamente uma investigação colaborativa é necessário que o pesquisador adote algumas posturas básicas. Compartilhe com os professores colaboradores todos os detalhes do processo de pesquisa; sensibilize-os para os princípios da Pesquisa Colaborativa, deixando claro o papel do pesquisador/mediador e dos professores colaboradores e faça o levantamento das necessidades formativas e dos conhecimentos prévios dos envolvidos na pesquisa, 
com o intuito de definir as temáticas que serão trabalhadas e o modo como os encontros seráo conduzidos, criando oportunidades para que sejam externalizados sentidos e significados, que ajudem na reorganização e ampliação dos níveis de conhecimento teórico e prático dos pesquisadores e dos professores.

Ao se referir à externalização de sentidos e significados e a apropriação de novos saberes teóricos e práticos, Ibiapina (2008) faz referência aos estudos de Vigotski (2000), no que tange ao processo de construção contínua das funçóes psíquicas superiores - pensamento, memória, atenção, formação de conceitos, emoção que se dá por meio da internalização do conhecimento acumulado socialmente (significado) que, no sujeito, ganha contorno próprio num processo reflexivo que parte de suas vivências pessoais (sentido). $\mathrm{Na}$ Pesquisa Colaborativa, isto ocorre na medida em que o pesquisador e os professores colaboradores elaboram suas experiências profissionais e os conhecimentos que possuem para compartilhar com o grupo. Assim, mediados pela fala do outro e por leituras teóricas, ampliam suas possibilidades de compreensão sobre a docência e constroem novas formas de pensar e atuar profissionalmente.

Inspirada nos escritos de Freire (2004) e Smyth (1992), Ibiapina (2008) propóe a organização das açóes reflexivas com base nos seguintes passos: a descrição detalhada da prática profissional; o contato com a informação, por meio do entendimento dos fundamentos que norteiam as escolhas feitas pelos professores no exercício de sua profissão; a confrontação que ocorre quando os professores buscam compreender de modo crítico o significado social de suas açóes e, por fim, a possibilidade de reconstrução da prática profissional.

$\mathrm{Na}$ pesquisa aqui referenciada, a ferramenta escolhida para proporcionar a construção desse processo reflexivo foi o desenvolvimento de sessóes reflexivas que, consiste em síntese, na realização de encontros com professores, organizados com o intuito de compartilhar significados e sentidos sobre um dado problema ou aspecto de sua prática profissional (IBIAPINA, 2008).

Foram desenvolvidas 16 sessôes reflexivas que compuseram o curso de extensão intitulado "Contribuiçóes da Psicologia Escolar Crítica para a prática pedagógica”. O curso, vinculado à Pró-Reitoria de Extensão, Cultura e assuntos estudantis da Universidade Federal de Uberlândia (PROEX/UFU) e ao Programa de Pós-Graduação em Educação (PPGED), aconteceu no espaço da própria Universidade, no período de agosto à dezembro de 2016, contando com encontros semanais de três horas e meia de duração cada.

O curso de extensão se constituiu na forma de um grupo colaborativo, conforme orientaçóes de Ibiapina (2008), do qual foram colaboradores, 11 professores licenciados que atuavam no Ensino Fundamental II e Médio de escolas públicas de Uberlândia e região. Além disso, a investigação restringiu-se aos professores que se encontravam nos seis primeiros anos de atuação profissional, ou seja, nas 
fases de "exploração" e "estabilização" da carreira. A fase de exploração, refere-se aos três primeiros anos de atuação profissional e é o momento em que o professor tem o contato inicial com a prática docente e busca sobreviver diante dos desafios apresentados. A fase de estabilizaçáo, por sua vez, vai dos quatro aos seis anos de experiência profissional e é o momento em que o docente define com mais clareza sua identidade profissional (MARCELO GARCIA, 1999).

As sessóes reflexivas foram apreendidas na íntegra por meio de audiogravação e foram, posteriormente, transcritas, transformando a palavra falada em texto, fazendo apenas pequenos ajustes condizentes às normas da escrita. Para complementar o material empírico produzido, utilizou-se também as anotaçóes da pesquisadora e dos professores feitas em diário de bordo, além dos materiais produzidos nos próprios encontros, tais como, desenhos, cartas, cartazes, etc.

Considerando as orientaçôes da pesquisa colaborativa, os cinco primeiros encontros foram dedicados a criação de vínculo en tre os participantes, a organização dos aspectos práticos e ao levantamento das expectativas e necessidades dos professores. Assim, todos os detalhes do curso de extensão e, consequentemente, da pesquisa foram definidos em grupo. As temáticas foram escolhidas a partir das demandas apresentadas pelos próprios professores colaboradores e, em síntese, abordaram os seguintes pontos: a estrutura física da escola, espaço, material, tradicionalismo; a agressividade, indisciplina, desinteresse, relação professorestudante; inclusão e atendimento educacional especializado; sexualidade, diversidade, preconceito, bullying; relacionamento com a direção, supervisão e colegas de trabalho, burocracia, falta de apoio e ser professor, remuneração, excesso de trabalho, formação contínua, autonomia, medos, saúde do trabalhador.

Para analisar o material empírico produzido pela pesquisa, optou-se pela metodologia dos Núcleos de Significação que orienta partir do empírico expresso na fala, nos gestos e demais elementos de comunicação registrados pelo pesquisador para, assim, compreender as zonas de sentido expressas pelos sujeitos de pesquisa (AGUIAR \& OZELLA, 2006; NAVES, 2011).

Assim, considerando todo o corpus de pesquisa construído na referida investigação a análise foi feita seguindo os seguintes passos: leitura cuidadosa do material empírico produzido; elaboração dos pré-indicadores de análise, destacando os trechos mais significativos; agrupamento dos pré-indicadores, por complementaridade, similaridade ou contradição, criando indicadores iniciais de compreensão dos dados; construção de núcleos de significação, elaborados a partir da organizaçáo dos indicadores, de modo a identificar zonas de sentido que ajudem na compreensão dos fenômenos investigados e, por fim, foi feita a análise dos núcleos de significação, por meio do exercício de articulação entre eles, os contextos mais amplos que constituem a realidade investigada e o referencial teórico pertinente (AGUIAR \& OZELLA, 2006; PEDRO, 2019) . 


\section{O processo de desenvolvimento profissional docente no grupo colaborativo}

Como ocorre o processo de desenvolvimento profissional docente no movimento de um grupo colaborativo? Essa foi a questáo problema que norteou a pesquisa aqui referenciada. Essa investigaçáo culminou na compreensão de que o processo de desenvolvimento vivido no e pelo grupo, ocorreu por meio de três zonas de sentido principais: a mediaçáo do outro, do meio, dos elementos estéticos e dos conhecimentos teóricos partilhados; o drama, a crise, a confrontação e experimentação do novo e a afetividade presente no modo como o grupo colaborativo foi construído e conduzido.

\section{1 "Eu nunca tinha pensado sobre isso, nessa perspectiva!": sobre a mediação no contexto do grupo}

Ao analisar o material empírico produzido pela pesquisa, foi possível identificar que os indicadores de análise que traziam indícios de transformação nas crenças e concepçôes sobre a docência e de ressignificação dos saberes profissionais tinham em sua raiz a mediação como princípio básico. No referido grupo colaborativo a mediação se deu, especificamente, no âmbito da relação com o outro, com a pesquisadora como psicóloga escolar, com os elementos estéticos, com o meio e os textos da Psicologia Escolar e Educacional numa vertente crítica que subsidiaram as conversas realizadas.

$\mathrm{Na}$ perspectiva da Teoria Histórico-cultural o homem se constitui como humano na medida em que estabelece relaçóes com o outro e o meio, mediado pela cultura (PINO, 2005). Na referida proposta de formação contínua foi possível observar, ao longo dos encontros, que os diálogos realizados entre os colaboradores evidenciavam o quanto o outro com sua subjetividade e experiência abria campo para que os demais entrassem em contato com aspectos importantes relativos à docência.

Como exemplo podemos citar o relato da professora Sara sobre um aluno que a xingou em sala de aula, que não pôde ser expulso, para não perder o "bolsa família" e que, segundo a professora, mesmo não tendo laudo, ela tem certeza de que o estudante tem problema mental. Ampliando a discussão acerca desse caso, fizemos a seguinte colocação: 
Pesquisadora: Vou fazer uma pontuação com relação a isso de ter laudo, de eu ter certeza de que um aluno tem algum problema. Essa tem sido uma fala comum entre nós. O senso comum se apropriou dos conhecimentos da psicologia e da psiquiatria e no dia a dia todos nós nos achamos no direito de diagnosticar o outro com base em nossas próprias percepçóes. Mas, vamos tomar esse caso que você trouxe Sara: um estudante que te xinga em sala de aula, que a diretora quer expulsar e, por isso, entra em contato com a familia por telefone. A família não comparece na escola e diz que a criança náo pode ser expulsa por conta do bolsa família. Será que esse contexto não determina o comportamento desse aluno? Será que de fato ele tem um problema psicológico ou psiquiátrico? Será mesmo que um laudo ou um remédio vai resolver seu problema? Isso é o que chamamos de medicalização da escola e da vida. É quando tornamos um problema social, em biológico ou genético. Isso tem se constituido uma válvula de escape em nossa sociedade, pois ao acreditar que o aluno tem uma doença e que precisa de um remédio, eu não crio condiçóes para que a escola mude, a educação se transforme, eu não converso com esse aluno e dou possibilidade para que ele aprenda, mude de postura, eu simplesmente dou o remédio e silencio os corpos.

Sara com uma postura reflexiva disse:

Sara: Nossa, eu nunca tinha pensado sobre isso nessa perspectiva! (Transcriçâo da $3^{\text {a }}$ sessão reflexiva)

Como é possível ver, no movimento do grupo colaborativo os professores foram transformando suas crenças e concepçóes sobre a docência e ressignificando seus saberes profissionais, indicando como o espaço de formação contínua construído estava mobilizando diferentes saberes que poderiam, posteriormente, ser acessados pelos professores para auxiliá-los em sua prática profissional.

Ressalta-se que esse processo de aprendizado demonstrado pelos colaboradores da pesquisa não ocorreu a partir de uma mediação qualquer. $\mathrm{Na}$ verdade, o grupo colaborativo, orientado por uma psicóloga escolar subsidiado pelos conhecimentos da Psicologia Escolar numa vertente crítica, se configurou como uma situação social propícia ao desenvolvimento docente. As vivências experimentadas no movimento do grupo colaborativo ressaltaram que o desenvolvimento do sujeito ocorre a partir de vivências que envolvem qualidades emocionais fortes, das quais náo conseguimos ficar indiferentes (TOASSA, 2008; MARQUES, CARVALHO, 2014). 


\section{2 "Eu não sei! Não sei! Eu não sei nada!": dos dramas e transformações vivenciados pelos professores colaboradores}

Consciente de que o homem é um ser social movido por situações dramáticas, logo, as interações sociais permeadas por colisão, oposição, contradição e conflito, promovem transformaçóes importantes no curso do desenvolvimento do sujeito (VERESOV, 2010). Nesse sentido, foi possível observar ao longo dos encontros formativos, que as crises vivenciadas pelos professores os ajudavam a elaborar novos sentidos sobre a docência e, consequentemente, construir práticas pedagógicas diferenciadas, além de colaborar na constituição da sua identidade profissional.

Quando se fez o levantamento das necessidades formativas dos professores, entre as informaçóes solicitadas, foi pedido que compartilhassem as crises que viviam na prática profissional. Para além desse momento específico, o grupo colaborativo configurou-se como espaço seguro para que os professores compartilhassem, segundo sua vontade, suas inseguranças, medos e contradiçóes.

A participação da professora Ane no curso de formaçáo proposto exemplifica como se dá o processo de desenvolvimento sob a mediaçáo do drama. Ane ao longo dos encontros, trazia falas enrijecidas e polêmicas, com pouca abertura para ver a docência e os estudantes numa perspectiva crítica. A professora revelou, inclusive, que não leu nenhum texto indicado como referência para os encontros. A despeito disso, no penúltimo encontro formativo em que foi proposto fazer uma síntese de todo o processo vivido a partir de algumas perguntas reflexivas, ao compartilhar a resposta para a questão "O que é ser professor para você?", Ane disse:

Ane: Eu não sei! Não sei! Eu não sei nada! Estou com vergonha. Eu coloquei que é estar diretamente conectada com os outros.

Pesquisadora: Legal.

Ane: Mas eu não sei se é legal. Eu acho que eu fiquei mais confusa depois que eu entrei aqui. Eu acho que ... eu não sei, eu não sei, eu não sei de nada.

Pesquisadora: Quando a gente entra em contato com uma coisa diferente do que a gente é, é normal que a gente se sinta confuso. [...] E para mim você se sentir confusa, soa como um retorno mais positivo do que negativo, Ane.

Cauã: Conhecendo um pouquinho de cada um de nós com o que expressamos aqui no grupo, eu concordo. Acho que, nesse caso, seu retorno Ane, é positivo. 
Pesquisadora: Quebom Cauâ, porque eu sinto quesinônimo de desenvolvimento profissional não é acúmulo de respostas, é acúmulo de questionamentos. Eu acho que quanto mais estamos questionando a nós mesmos, o mundo, nosso trabalho, estamos inquietos, não estamos satisfeitos com o ponto em que nos encontramos, entáo estamos querendo outra coisa, queremos nos transformar, ser melhores. E até descobrirmos como nos colocar no mundo de outra forma, como é esse novo lugar, é comum que a gente se sinta um pouco perdido.

Para explicar minha fala, Cauã deu um exemplo no quadro usando círculos para mostrar que o universo que corresponde àquilo que não sabemos é sempre maior do que aquilo que sabemos. E Ane disse que tinha a sensação de que quanto mais buscava conhecer as coisas, mais sentia que não sabia.

Pesquisadora: Se os meus pontos de interrogação aumentam, eu começo a ficar mais cuidadosa comigo como pessoa, com a minha profissão. Antes eu não me importava, mas agora que eu tenho um incômodo, eu me preocupo, eu fico angustiada e isso gera mudança, transformação. Para mim, isso é bom Ane, porque significa que alguma coisa está mudando dentro de você e que algo novo está querendo se manifestar.

Ane: Eu entendo e acho que estou falando que eu não sei, não sei nada, porque no exercício de completar frases eu respondi coisas que já nem sei se acredito, não tenho certeza sobre elas. Eu estava respondendo e enquanto escrevia já estava incomodada, achando que não era bem assim.

Pesquisadora: Que legal Ane, porque o exercício de escrever como num brainstorm, sem filtrar os pensamentos, é justamente para que a gente consiga expressar com mais verdade o que está dentro da gente, sem racionalizar tanto. [...] Assim, podemos acessar as nossas crenças mais arraigadas, aquilo que nos move. [...] Então, quando você diz que enquanto você estava escrevendo, o incômodo já ia surgindo, para mim isso é muito positivo, pois o que vem no automático é aquilo que já está naturalizado e quando eu não me reconheço mais naquilo, eu vejo aí um sinal de mudança. A mudança pode não ter sido elaborada o suficiente para ser verbalizada, mas ela está sendo gestada (Transcrição da $14^{a}$ sessão reflexiva).

Acompanhando os processos vivenciados por Ane e os demais professores no movimento do grupo colaborativo, foi possível verificar como o desenvolvimento tem um caráter turbulento e se assemelha a um curso revolucionário de eventos que desencadeiam mudanças (VIGOTSKI, 1998). Como seres sociais, vivemos imersos em interaçóes que segundo sua intensidade emocional movem nosso processo de constituição como humanos. 
No grupo, a vivência entre os colaboradores naquele contexto, bem como a partilha das situaçóes dramáticas vividas pelos professores em seu ambiente de trabalho, fazia emergir as diferentes crises experimentadas pelos professores na relação com a docência. Assim, as crises evidenciaram-se como uma complexa combinação de aspectos do ambiente e do sujeito, uma vez que nem o meio e nem o homem, de forma isolada promovem mudanças no curso da vida. É a forma como o sujeito apreende e se relaciona com o contexto do qual faz parte que determina sua constituição subjetiva (VERESOV, 2015). Esse ponto de encontro entre a vivência dramática e o meio, que se dá de maneira única em cada sujeito, acontece em situaçóes sociais de desenvolvimento específicas que transcendem a simples experiência externa de algo, configurando-se como o momento disparador de mudanças qualitativas no psiquismo humano. Nesta pesquisa, esse espaço-tempo propício ao desenvolvimento profissional do professor foi o grupo colaborativo.

4.3 "Nossa, a gente se constituiu como grupo de uma forma tão intensa!": das especificidades do grupo colaborativo e a repercussão no processo de desenvolvimento profissional docente

Na referida pesquisa, o grupo colaborativo evidenciou-se como uma situação social propícia ao desenvolvimento profissional do professor e isso não se deu naturalmente, mas sim devido a escolhas específicas que tomamos como pesquisadora.

A opção por seguir cuidadosamente as orientaçóes da pesquisa colaborativa, considerando a horizontalidade nas relaçóes, a tomada de decisão de forma democrática e a comunicaçáo clara entre os colaboradores da pesquisa (IBIAPINA, 2008), logo, culminou em indícios de colaboração efetiva. Para isso, algumas ferramentas foram utilizadas: a busca por conhecer os participantes de modo mais aprofundado, compreendendo os aspectos profissionais e pessoais que determinam a sua constituição; a investigação dos conhecimentos prévios dos professores e suas necessidades formativas; a construção de um contrato em grupo com orientações sobre a forma de estar no grupo; o acolhimento dos participantes a cada encontro com um saboroso e cuidadoso lanche; a escrita de uma carta reflexiva sintetizando todo o processo vivido.

Todas essas decisóes pedagógicas adotadas para a conduçáo do grupo colaborativo evidenciaram a importância da afetividade nos espaços de aprendizagem, uma vez que, "[...] os processos afetivos complexificam-se durante o desenvolvimento, sofrem influência e influem nos processos cognitivos, mantendo com eles uma relaçáo dialética durante toda a vida do sujeito (LEITE, 2017, p. 163).

Ao considerar que o homem é uno e que os aspectos cognitivos e afetivos coexistem no ser afetando-o mutuamente, Vigotski (1998) aponta que as 
emoçóes, tomadas por ele como funçóes psicológicas superiores, determinam o desenvolvimento dos sujeitos. Se as emoçôes são histórico-culturalmente determinadas e nascem das interações sociais entre os homens, logo, no contexto da sala de aula a relaçáo professor-estudante é marcada por afetos. Como o professor é o principal responsável pela mediação entre os conhecimentos historicamente produzidos e os estudantes, consequentemente, a qualidade da mediação realizada por ele no contexto da sala de aula, determina a relaçáo do estudante com um dado conteúdo, podendo gerar uma resposta de aproximação ou afastamento. $\mathrm{O}$ mesmo se dava em nosso curso de formação contínua, em que evidenciou-se como fundamental a relaçáo entre afetividade, práticas pedagógicas e aprendizagem (LEITE, 2012).

Nesse sentido o relato do professor Thiago em seu diário de bordo aponta para a importância de valorizar a afetividade na relação professor-aluno, no caso, pesquisador-colaboradores, a partir do uso de estratégias pedagógicas que estabeleçam vínculos positivos e uma relação de aproximação entre os sujeitos e o objeto de ensino.

Thiago: Pensar todos juntos o desenvolvimento do curso é algo novo para mim. Levantar temas, saber as demandas dos cursistas é ótimo. Buscar entender os anseios de cada um é bacana. Fico com medo. Estabelecer contrato é importante porque agrega responsabilidade para todos os participantes. Equando você se vê fazendo parte da construção do curso, a noção de pertencimento é bem maior. [...] Quando estabelecemos vinculos entre os alunos, eles também ganham responsabilidade, porque sabem o quanto sáo construtores no processo ensino aprendizagem (Diário reflexivo - Thiago).

A fala de Thiago traz uma reflexão muito significativa, pois elucida que pensar em afetividade na escola é realmente algo novo, uma vez que secularmente esse espaço valoriza e prioriza o desenvolvimento cognitivo em detrimento das questôes emocionais e sociais, como se o homem fosse cindido. A despeito disso,

[...] deve-se destacar que os processos afetivos complexificam-se durante o desenvolvimento, sofrem influência e influem nos processos cognitivos, mantendo com eles uma relação dialética durante toda a vida do sujeito. (LEITE, 2017, p. 163)

Compreendemos, portanto, que toda interação é afetiva, pois envolve emoçóes e sentimentos que determinam à subjetividade do homem. Logo, valorizar a afetividade como professor, é reconhecer os estudantes e a si próprio como seres unos, 
constituídos por aspectos biológicos, cognitivos, afetivos, sociais e psicológicos e a partir disso, fazer escolhas pedagógicas que busquem estabelecer vínculos positivos, de aproximação entre os alunos, o professor e os objetos de ensino.

Em seus estudos, Leite (2012) aponta cinco decisóes pedagógicas que quando utilizadas de forma adequada pelo professor, podem desencadear impactos afetivos positivos na relação dos estudantes com o objeto de ensino, favorecendo a aprendizagem. Trata-se: da escolha dos objetivos de ensino; da decisão sobre o início do processo de ensino; da organização dos conteúdos de ensino; da organização dos procedimentos e atividades de ensino e da escolha dos procedimentos de avaliação do ensino. Na pesquisa aqui referenciada, as decisóes pedagógicas tomadas no movimento de condução do grupo colaborativo, foram ao encontro das propostas por Leite (2012), reverberando positivamente na qualidade do vínculo estabelecido no grupo e, consequentemente, nos processos de transformação e desenvolvimento vividos pelos professores.

\section{Do desenvolvimento profissional docente ao desenvolvimento humano - o grupo colaborativo e seu potencial mediador}

A partir da referida investigação, foi possível concluir que o grupo colaborativo configurou-se como um mediador profícuo não só ao desenvolvimento profissional dos professores colaboradores da pesquisa, mas ao desenvolvimento deles como humanos. Para Veresov (2010), o desenvolvimento humano envolve um processo complexo de reorganização das funções psicológicas superiores, resultado de mudanças qualitativas no psiquismo humano. Ao analisarmos os relatos dos professores identificou-se transformaçóes no psiquismo destes, especialmente, no que se refere à construçáo de novos conceitos, à reflexividade do pensamento, à imaginação criadora e à capacidade de elaboração das emoçóes.

O coletivo de professores construído ao longo da investigação, constituiuse como um mediador importante para o desenvolvimento dos professores colaboradores da pesquisa. O clima de colaboraçáo presente nos encontros possibilitou processos de reflexão, confrontação, conscientização, sensibilização e criação que culminaram em mudanças no âmbito pessoal e profissional dos docentes.

Considerando que a investigação em questão teve como objetivo apreender e analisar o processo de desenvolvimento profissional docente no movimento de um grupo colaborativo, apresenta-se a seguir algumas sínteses importantes para o campo de estudo científico sobre a docência. Primeiramente, verificou-se que o grupo construído, a partir das orientaçóes de Ibiapina (2008) sobre a Pesquisa 
Colaborativa, constituiu-se como fonte de desenvolvimento docente. Foi possível observar que o processo de desenvolvimento docente tem como importante motor a mediação do outro e os dramas vividos pelos professores. Destacou-se também que as crises vivenciadas pelos docentes tiveram peso importante em seu processo de desenvolvimento, uma vez que são as vivências marcadas por caráter de conflito que se caracterizam como verdadeiros dramas, que repercutem em transformaçóes no curso do desenvolvimento do sujeito. Por isso, afirma-se a importância de haver momentos na docência para a partilha entre colegas de profissão, com mediaçáo e orientação adequadas, visando contribuir com o processo de transformação e construção da identidade profissional. Por fim, foi possível considerar que as relações sociais envolvem emoçôes e, por isso, também são afetivas. Logo, nos contextos de aprendizagem, a afetividade é determinante para que haja uma relação de aproximação entre os sujeitos e os objetos de ensino e o professor/mediador é o responsável pelo estabelecimento de um clima afetivo nos espaços de ensino.

Enfim, faz-se importante ressaltar que o potencial do grupo colaborativo em questão se deu a partir da utilização de alguns pressupostos que podem inspirar a organização de futuros espaços de formação contínua de professores. São estes: o planejamento cuidadoso do curso de extensão tendo claro os referenciais teóricos utilizados para subsidiar as sessóes reflexivas; o esclarecimento dos objetivos da pesquisa junto ao grupo; a construção de um contrato coletivo; a organizaçáo dos encontros fazendo uso de diferentes recursos didáticos; o estabelecimento de uma postura horizontal e democrática para com todos; ter a afetividade como guia para orientar as relaçóes entre os professores; propor uma escuta atenta e ativa; ter uma postura cuidadosa para com os detalhes da pesquisa; conduzir a pesquisa com sensibilidade e flexibilidade; reconhecer as próprias falhas como mediadora do grupo; utilizar a Arte como mediadora dos diálogos; considerar o contexto histórico, cultural e político no qual o grupo estava inserido; a valorização dos aspectos pessoais e subjetivos dos colaboradores; a realização de avaliaçóes e feedback ao longo do processo, além da expressão, como mediadora, do amor pela docência e pela educaçáo.

Tudo isso repercutiu em transformaçôes nos professores e em suas práticas pedagógicas, demonstrando que o movimento do grupo colaborativo foi fundante da dimensão formativa para a construção identitária, para a ressignificação dos saberes docentes e elaboração de novos saberes, portanto, para o desenvolvimento profissional dos professores. Além de evidenciar que o desenvolvimento profissional abrange também o desenvolvimento do professor como sujeito uno, singular e subjetivo que exerce uma profissão dotada de complexidade em que as dimensóes pessoais e profissionais são indissociáveis. Apontando, por fim, para a importância da construçáo de coletivos de professores que possibilitem transcender os caminhos solitários da docência, para encontros solidários, por 
meio da construção de parcerias colaborativas e fraternas voltadas à emancipação e transformação do humano, da educação e da sociedade.

\section{Referências}

ASBAHR, F. S. F. Sentido pessoal e projeto político pedagógico: análise da atividade pedagógica a partir da psicologia histórico-cultural. Dissertação de Mestrado, Instituto de Psicologia, Universidade de São Paulo, São Paulo, 2005.

BEHRENS, M. O paradigma da complexidade na formação e no desenvolvimento profissional de professores universitários. In: Educaçáo. Porto Alegre. N. 3. 2007. p. 439-455.

BRASIL. Ministério da Educação e Cultura. Resoluçâo CNE/CP 01/2002, de 18 de fevereiro de 2002. Diretrizes Curriculares Nacionais para a Formaçáo de Professores da Educaçáo Básica, em nível superior, curso de licenciatura, de graduação plena. Brasília, 2002. Disponível em: http://portal.mec.gov.br/cne/ arquivos/pdf/rcp01_02.pdf. Acesso em: 02 de outubro de 2016.

BRASIL. Lei 13.005 de 25 de junho de 2014. Plano Nacional de Educação PNE. Diário Oficial da União. Brasília: Senado, 2014. Disponível em: http:// www.jusbrasil.com.br/diarios/72231507/dou - edição - extra - seção -1-26-06 2014 - pg - 1. Acesso: 02 de outubro de 2016.

BRASIL. Ministério da Educação e Cultura. Resolução CNE/CP 02/2015. Diário Oficial da União, Brasília, 02 de julho de 2015.

DUBAR, C. A socializaçáo: construçáo das identidades profissionais e sociais. Porto: Lisboa. Vol. 24. Coleção Ciência da Educação, 1999.

FONTANA, R. A C. Como nos tornamos professoras? Aspectos da constituição do sujeito como profissional da educação. Tese (Doutorado), Faculdade de Educação, Universidade Estadual de Campinas, Campinas, 1997.

GAUTHIER, C. Por uma teoria da Pedagogia - Pesquisas contemporâneas sobre o saber docente. Ijuí/RS: Ed. Unijuí, 1998.

GIROUX, H. A. Os professores como intelectuais: rumo a uma pedagogia crítica da aprendizagem. Porto Alegre: Artmed, 1997.

GONZÁlES REY, F. Pesquisa Qualitativa e Subjetividade: os processos de construção da informação. Tradução: Marcel Aristides Ferrada Silva. São Paulo: Thomson, 2005. 
IBIAPINA, I. M. L. de M. Pesquisa Colaborativa: investigação, formação e produção de conhecimentos. Brasília: Líber Livro Editora, 2008.

LEITE, S. A. S. Afetividade nas práticas pedagógicas. Temas em Psicologia. Vol. 20, no 2. 2012.

LEITE, S. A. da S. A afetividade como objeto de pesquisa. In: BORUCHVITCH, E.; AZZI, R. G.; SOLIGO, a. (Org.) Temas em Psicologia Educacional: contribuiçóes para a formação de professores. Campinas: Mercado das Letras, 2017.

LEONTIEV, A. N. O desenvolvimento do psiquismo. Lisboa: Horizonte Universitário, 1978.

MARCELO GARCIA, C. Formaçáo de Professores: para uma mudança educativa. 1999.

MARCELO GARCIA, C. Desenvolvimento Profissional Docente: passado e futuro. Sísifo. Revista de Ciências da Educaçáo, n.8, jan-abr, 2009, pp. 7-22.

MOREIRA, A. F. Currículos e programas no Brasil. Campinas: Papirus, 1990.

NÓVOA, A. (coord.) Os professores e a sua formaçáo. Lisboa: Dom Quixote, 1992. ISBN 972-20-1008-5. pp. 13-33. Disponível: http://hdl.handle. net/10451/4758. Acesso: 9 de fevereiro de 2017.

PEDRO, L. G. Como se fora brincadeira de roda - o grupo colaborativo como mediador do desenvolvimento docente. Tese de Doutorado. Faculdade de Educação, Universidade Federal de Uberlândia, Uberlândia, 2019.

PIMENTA, S. G. (org.). Saberes Pedagógicos e Atividade docente. São Paulo: Cortez, 2000.

PINO, A. As marcas do humano: as origens da constituição cultural da criança na perspectiva de Lev S. Vigotski. Sáo Paulo: Cortez, 2005.

PRESTES, Z. Quando náo é quase a mesma coisa: análise de traduções de Lev Semionovitch Vigotski no campo educacional. Tese (Doutorado) - Faculdade de Educação da Universidade de Brasília, Brasília, 2010.

SMOLKA, A. L. B. Sobre significação e sentido: uma contribuição à proposta de rede de significaçóes. In M. C. ROSSETTI-FERREIRA, K. S.; AMORIM, A. P. S.; SILVA, A. M. A. Carvalho (orgs.), Rede de significaçóes e o estudo do desenvolvimento humana. Porto Alegre: Artes Médicas, 2004.

SOUZA, M. P. R. Políticas públicas e educação: desafios, dilemas e possibilidades. In: VIEGAS, L. S.; ANGELUCCI, C. B. (Orgs.). Políticas públicas em Educaçáa: uma análise crítica a partir da Psicologia Escolar. São Paulo: Casa do Psicólogo, 2006. 
TARDIF, M. Saberes Profissionais dos Professores e conhecimentos universitários. Revista Brasileira de Educaçáo. São Paulo, n. 13, p. 03-24. Jan./abr 2000.

TARDIF, M. Saberes docentes e formação profissional. Petrópolis, RJ: Vozes, 2011.

TOASSA, G. Emoçóes e vivências em Vigotski: investigação para uma perspectiva histórico-cultural. Tese de Doutorado, Instituto de Psicologia, Universidade de São Paulo, São Paulo, 2009.

VERESOV, N. Introducing cultural-historical theory: main concepts and principles of genetic research methodology. Cultural-historical psychology, 4, 83-90, 2010. Disponível em:http://nveresov.narod.ru/KIP.pdf Acesso em 15 Set 2018.

VERESOV, N. Duality of Categories or Dialectical Concepts? Integrative Psychological and Behavioral Science, v. 50, 244-256, 2015. Disponível em: DOI 10.1007/s12124-015-9327- 1 Acesso em: 20 Nov 2018.

VIGOTSKI, L. S. The Diagnostics of Development and the Pedological Clinic for Difficult Children. In: The Collected Works of L. S. Vygotsky: The Fundamentals of Defectology (Vol. 2, p. 241-291). New York: Spriger Science+Business Media New York, 1997.

VIGOTSKI, L. S. Aprendizagem e desenvolvimento na idade escolar. In: VIGOTSKI, L.S.;LURIA, A. R.; LEONTIEV,A. N. Linguagem, desenvolvimento e aprendizagem. São Paulo: Ícone, 1988.

VIGOTSKI, L. S. The problem of environment. In: R. VAN DER VEER, R.; VALSINER, J. (Eds.). The Vygotsky reader. Oxford: Blackwell, 1998.

VIGOTSKI, L. S. A formação social da mente. São Paulo: Martins Fontes, 2000.

VIGOTSKI, L. S. Quarta aula: a questáo do meio na pedologia. Psicologia USP. São Paulo, 21(4), 2010. 